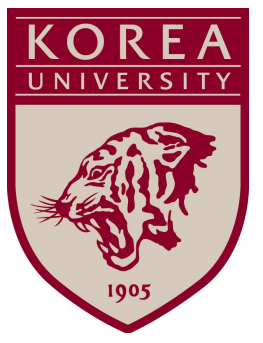

Discussion Paper Series

No. 1001

Jan 2010

\title{
Inheritances, Health and Death
}

\author{
Beomsoo Kim and Christopher J. Ruhm
}

The Institute of Economic Research - Korea University

Anam-dong, Sungbuk-ku, Seoul, 136-701, South Korea, Tel: (82-2) 3290-1632, Fax: (82-2) 928-4948

Copyright (c) 2010 IER. 


\title{
Inheritances, Health and Death ${ }^{*}$
}

\author{
Beomsoo Kim \\ Korea University \\ kimecon@korea.ac.kr \\ Christopher J. Ruhm \\ University of North Carolina Greensboro \\ and National Bureau of Economic Research \\ chrisruhm@uncg.edu
}

December 2009

\begin{abstract}
We examine how wealth shocks, in the form of inheritances, affect the mortality rates, health status and health behaviors of older adults, using data from eight waves of the Health and Retirement Survey (HRS). Our main finding is that bequests do not have substantial effects on health status, although some improvements in quality-of-life are possible. This absence occurs despite increases in out-of-pocket (OOP) spending on health care and in the utilization of medical services, especially discretionary and non-lifesaving types such as dental care. Nor can we find a convincing indication of changes in lifestyles that offset the benefits of increased medical care. Inheritances are associated with higher alcohol consumption, but with no change in smoking or exercise and a possible decrease in obesity.
\end{abstract}

*We thank Mark Votruba, Michael Hurd and seminar participants at the University of Bristol, University of Oslo, RAND and the Southern Economic Association meetings for helpful comments on an earlier draft of this paper. 


\section{INTRODUCTION}

Do improving economic circumstances lead to better health? At first blush the answer seems obvious. Economic theory predicts that higher wealth will relax the budget constraint, allowing individuals to obtain more of all normal goods, presumably including health (Grossman, 1972). A great deal of research, across a variety of disciplines, suggests a positive relationship between social or economic advantage and health (Kitagawa and Hauser, 1973; Marmot et al., 1984, 1991; Feinstein, 1993). However, such cross-sectional associations are less convincing than they first appear because of the possibility of reverse causation - whereby health determines economic circumstances rather than vice versa (Smith, 1999) - or if there are omitted confounding factors (such as discount rates) that cause both health and economic status (Fuchs, 1982). Moreover, time series data often tells a different story. For instance, many types of physical health worsen when the economic conditions temporarily improve (Ruhm, 2000, 2005, 2007). Wealth effects might also vary across the lifecycle, with some analysts emphasizing the particular importance of economic circumstances at young ages (Wadsworth \& Kuh, 1997; van den Berg, 2006).

This paper investigates how inheritances are related to mortality, health status and health behaviors. Our data come from the first eight waves of the Health and Retirement Survey (HRS), a large U.S. longitudinal survey of adults 51 and older. Bequests are useful to examine because they frequently represent large and unanticipated or not fully anticipated shocks. As such they can be thought of as pure income effects, in contrast to wage increases that contain a potentially offsetting substitution component. The HRS contains multiple measures of health, as well as data on a wide variety of individual characteristics including health status prior to inheritance receipt.

Beyond focusing on bequests, which have been rarely studied in this context, our analysis improves upon most related previous research in several ways. First, we take extra care in 
accounting for potential confounding factors by controlling for a wide variety of characteristics, including baseline health status, and by incorporating a falsification-based framework whereby the predicted "effects" of inheritances too small to plausibly influence health are attributed to unobserved heterogeneity and are subtracted from those of larger bequests. Second, we separately examine how inheritances are related to future mortality and to several measures of health status among the living. Third, we explicitly consider the role of multiple types of medical care in explaining any observed changes in health. Finally, we examine whether bequests affect lifestyle behaviors that have potential consequences for health.

Our main finding is that the wealth shocks associated with sizable inheritances do not substantially affect the health of senior citizens, although some improvements in quality-of-life are possible. The point estimates suggest a small (statistically insignificant) rise in overall mortality, but with some possibility of modest benefits for men as well as small or imprecisely estimated improvements in some health measures. The absence of strong health impacts comes despite increases in out-of-pocket (OOP) health care spending and in the utilization of many types of medical services, particularly those with a large discretionary component. Nor can we find convincing evidence of offsetting changes in lifestyles. The positive wealth shocks raise light drinking, with no change in smoking or vigorous exercise, and some indication of lower obesity prevalence.

\section{QUASI-EXPERIMENTAL ESTIMATES}

Potential biases due to reverse causation or confounding factors limit what we learn from previous evidence of positive cross-sectional associations between economic circumstances and health. An ideal experimental design would provide sizable wealth shocks to randomly assigned individuals, whose health could then be compared over several years to otherwise similar persons. 
Since such experiments are impractical, a potentially promising alternative is to obtain estimates that are "quasi-experimental", in that they exploit natural experiments or use econometric identification strategies that mimic experimental designs.

Such approaches contain inherent limitations, relative to the experimental "gold standard”, if the variation is not truly random, the treatment group does not represent the full population, or the size and nature of the shocks are limited. For instance, like many related studies, our analysis focuses on mature adults. This is restrictive if socioeconomic status (SES) related health gradients initially grow with age but narrow later in life (Deaton and Paxon; Case et al., 2002; Smith, 2004), since wealth might then not affect the health of senior citizens while having important benefits at younger ages. ${ }^{1}$ Quasi-experimental approaches nevertheless hold promise for providing information on how wealth shocks affect the groups considered and for types of variation available in the data. Although we do not attempt to comprehensively review the prior literature, the remainder of this section characterizes the main results obtained from previous quasi-experimental approaches and supplies context for understanding the contribution of the current analysis.

Instrumental variables (IV) models provide a standard econometric method for dealing with the endogeneity. Ettner (1996) provides the best known example in this literature. Using data from several sources, she finds that income is positively related to health as proxied by selfreported overall status, bed-days, limitations in activities of daily living (ADLs) and depression scores; stronger associations are obtained from IV than ordinary least squares (OLS) estimates. ${ }^{2}$ As is typical, the challenge is in finding valid instruments - that are correlated with income but

\footnotetext{
${ }^{1}$ The SES-health gradient may be smaller for senior citizens for purely biological reasons - e.g. if the marginal product of medical care declines beyond a certain age - or because senior citizens in the United States have almost universal (albeit often incomplete) health insurance through Medicare, whereas younger persons do not.

${ }^{2}$ Stronger IV estimates could occur because the unobserved characteristics of high income persons result in relatively poor health (which seems unlikely) or because measurement error attenuates the OLS coefficients.
} 
do not independently affect on health - and several of those used by Ettner (e.g. state unemployment rates and education of the spouse or parents) may directly influence health.

Mixed results have been obtained using a second procedure that exploits variations in cohort-specific incomes. Deaton and Paxon (1998) show that cohort- incomes are positively related to health in the United States, with the strongest effects observed in middle-age, whereas Adda et al. (forthcoming) fail to uncover such a correlation for the United Kingdom. These conflicting results could reflect cross-country differences or limitations of the estimation strategy. Specifically, reverse causation due to individual health status is eliminated but cohort level biases are not: better average health might cause cohort incomes to rise and omitted factors (e.g. medical technologies or lifestyle changes) could be correlated with average levels of cohort health and income.

A third strategy exploits government policies creating plausibly exogenous variations in wealth. Case (2004) finds that pension reforms leading to unanticipated increases in the wealth of black and coloured South Africans were associated with health improvements. ${ }^{3}$ Such results might not extend to industrialized countries, however, with Snyder and Evans (2006) providing countervailing evidence of reduced mortality rates for U.S. seniors whose retirement wealth was unexpectedly lowered due to the Social Security benefit "notch". Interestingly, they suggest that health improved due to higher rates of (part-time) post-retirement employment which, in turn, were hypothesized to reduce social isolation and increase connections with the community. These results do not necessarily generalize to younger individuals or to wealth increases unaccompanied by changes in labor supply. ${ }^{4}$

\footnotetext{
${ }^{3}$ These health benefits were shared by all family members in households that pooled incomes.

${ }^{4}$ Similarly, Frijters et al. (2005) find that the increased incomes experienced by East Germans, following German unification, resulted in only slightly higher levels of health satisfaction, although their experimental design combines the impact of pure income shocks (due to currency conversion) with wage changes that may generate additional substitution effects.
} 
Finally, a number of researchers examine how health is affected by individual income or wealth shocks. Lindahl (2005) shows that, among Swedish lottery winners, larger prizes are associated with better health and lower mortality rates, with bigger estimated effects from IV than OLS models. However, his sample is limited to winners and he has no information on the frequency of lottery playing. Gardner and Oswald (2007) attempt to overcome these problems, by comparing the consequences of medium size $(£ 1000-£ 120,000)$ UK lottery winners to those receiving small prizes $(<£ 1000)$ not expected to affect health. ${ }^{5}$ They find that medium size prize winners report reductions in mental stress, although the effects take two years to show up. A general concern is that lotteries could influence health through channels other than income. For instance, winning a large lottery might place stress on social relationships (Kaplan, 1978). As an alternative, Smith (2004) examines the effects of changes in stock market wealth and fails to uncover any connection with health. However, this could occur because such fluctuations are viewed to be transitory or uncertain.

This study examines inheritances. As mentioned, bequests frequently represent large wealth shocks that, unlike wage changes, have no offsetting substitution effect. Inheritances also are potentially received by a wide cross-section of the population, in contrast to lotteries that can only be won by players. ${ }^{6}$ Using inheritance as an exogenous shock is not perfect. That said, inheritance shocks are not without problems of their own. One potential issue is that inheritances need not always be unanticipated, raising the possibility of changes in health or lifestyles prior to their actual receipt, and probably leading to an understatement of the effects in our analysis. However, even when anticipated (with some probability), the amount and timing of bequests are uncertain, making it likely that many individuals feel constrained in using the prospective future

\footnotetext{
${ }^{5}$ The assumption is that small and medium prize winners are likely to have similar unobserved characteristics, since both play the lottery.

${ }^{6}$ Similarly, the effects of stock market shocks are complicated since individual returns depend on each person's (endogenously determined) stock portfolio.
} 
wealth prior to its actual receipt. We provide evidence below that our results are not sensitive to accounting for the subjective ex ante probability of inheriting and show that individuals frequently have difficulty correctly predicting the probability of obtaining future bequests.

A more serious concern is that inheritances may be correlated with unobserved determinants of health. This may be an issue for Meer et al. (2003), who use inheritances to instrument changes in wealth and uncover what they describe as weak improvements in selfassessed health status. ${ }^{7}$ Michaud and van Soest (2008) similarly instrument changes in wealth with bequests. They present statistical evidence indicating the importance of unobserved heterogeneity and argue that accounting for it completely eliminates the causal effects of wealth on health. ${ }^{8}$

We use three strategies to minimize potential omitted variables biases. First, we take advantage of the substantial information available in the Health and Retirement Survey to account for a wide variety of observable characteristics. Our analysis suggests that such controls are important, since bequests are not received randomly but instead tend to be obtained by persons with characteristics correlated with good health. More comprehensive controls therefore reduce the estimated health benefits of inheritances. Second, we hold constant health status and behaviors at baseline (prior to the potential receipt of an inheritance). Previous research (Adams et al., 2003; Gardner and Oswald, 2007) demonstrates the usefulness of examining health innovations in this way, and these covariates account for important sources of otherwise uncontrolled for heterogeneity. Lastly, we incorporate an implicit "falsification test”, focusing on the differential impact of a substantial inheritance over and above that of small bequests

\footnotetext{
${ }^{7}$ This characterization can be questioned. A $\$ 250,000$ inheritance increases the predicted probability of good health by two percentage points, on a base of 81 percent, which Meer et al. consider to be small. However, this equivalently reduces the probability of poor health by two points on a base of 19 percent, which seems substantial. This study also contains other limitations. For example, self-assessed health is the only outcome examined and a limited set of covariates are accounted for.

${ }^{8}$ However, their identification strategy is quite different than ours and they examine a shorter time period, a more restrictive sample, and a less comprehensive set of outcomes than we do.
} 
expected to have no (or at most tiny) health consequences. Specifically, our main specifications focus on the incremental effect of inheritances of $\$ 10,000$ or more. It seems unlikely that bequests below $\$ 10,000$ (averaging under $\$ 4,300$ ) affect health much. Conversely, inheritances above this threshold average almost \$114,000 (in 2002 year dollars) and so are large in both absolute terms and as a share of lifetime income. ${ }^{9}$ We also estimating models where inheritances are classified as "large" or "small" based on their size as a proportion of baseline income, rather than using an absolute dollar amount.

\section{DATA AND OUTCOMES}

\subsection{Health and Retirement Survey}

Our analysis uses longitudinal data from the initial cohort of the Health and Retirement Survey (HRS), consisting of persons born from 1931 to 1941, and their spouses. The first interview took place in 1992, with seven additional survey waves at two-year intervals through 2006. ${ }^{10}$ This age group and data set have several advantages. Mortality and morbidity are prevalent among seniors ${ }^{11}$, potentially making it easier to observe the health effects of wealth shocks. The chance of receiving an inheritance also increases with age and the HRS contains detailed information on individual characteristics, health and mortality.

In each survey wave, HRS respondents were asked:

"People sometimes receive property or lump sum payments of money from such things as pension settlements, insurance settlements, cashing in annuities, or inheritances. In

\footnotetext{
${ }^{9}$ An \$114,000 inheritance represents around 2.4 years of income, at the sample average.

${ }^{10}$ The HRS added four cohorts - the Study of Assets and Health Dynamics Among the Oldest Old (AHEAD), Children of Depression (CODA), War Baby (WB), and Early Baby Boomers (EBB), in 1993, 1998, 1998 and 2004 respectively. We do not incorporate these cohorts in our analysis.

${ }^{11}$ For example, 29.2 percent of persons born before 1946 received an inheritance by 2004, compared to 18.4 percent of those born between 1946 and 1964, and 12.1 percent of those born after 1964 (Gist \& Figueiredo, 2006).
} 
the past two years did you [or your (husband/wife/partner)] receive a lump sum of money or property worth $\$ 500$ or more that you have not already told me about?"12

An affirmative answer led to queries about the source of lump sum (e.g. insurance or pension settlement, inheritance, or annuity) and we use these responses to limit the wealth shock analyzed to inheritances. ${ }^{13}$ Respondents were also questioned about the amount of the bequest, with information on bracketed values of more or less than $\$ 50,000$ requested for persons not specifying an exact amount. We converted inheritances to 2002 dollars (using Current Price Index) and substituted the average amount conditional on receiving less (more) than $\$ 50,000$ for persons providing categorical information. ${ }^{14}$

The original HRS cohort contains 12,652 persons at the baseline (1992) interview. We restrict our sample in three important ways. First, we exclude respondents receiving a bequest before the 1992 survey, since we do not have pre-inheritance information for them. Second, our analysis is limited to whites. The reason for this is pragmatic. Blacks have low probabilities of inheriting and obtain relatively small amounts when they do: just 5.7 percent obtained a bequest (after 1992) and only 3.5 percent received $\$ 10,000$ or more, compared to 23.5 and 17.0 percent of whites (see Table 1 ). The average inheritance amount for whites is $\$ 20,449$ and conditional upon receipt (receipt more than $\$ 10,000$ ) it is $\$ 87,015$ (\$113,909). Sex differences in bequest receipt and size are modest. Third, the HRS includes spouses of persons born between 1931 and

\footnotetext{
12 The wording changed slightly across survey waves. For example, the first interview asked "whether you ever received an inheritance till now", instead of using the last two years as the time-frame.

${ }^{13}$ Our rationale is that other shocks could affect health for reasons unrelated to changes in wealth. For example, insurance settlements due to auto accidents could represent compensation for harm caused to health, and annuities are frequently the anticipated realizations of wealth flows from savings earlier in life.

${ }^{14}$ The average is $\$ 17,276(\$ 186,509)$ conditional on a bracketed inheritance amount less (greater) than $\$ 50,000$. We use the original HRS data for the inheritance-related variables. All other information comes from the RAND HRS Data (version $\mathrm{H}$ ), which has been cleaned and transformed to be user-friendly and accessible to researchers (Rand, 2008).
} 
1941, regardless of their age. ${ }^{15}$ To maintain a fairly homogeneous sample, we restrict spouses to those born within five years of the original cohort (between 1926 and 1946). ${ }^{16}$

Attrition is potentially problematic, since $16.4 \%$ of respondents dropout prior to the wave 8 interview. Some of this may represent unidentified deaths, which we account for when analyzing mortality by censoring such observations at the time of attrition. However, this could be an issue for evaluating health status, since persons exiting the sample could differ systematically from those who do not. To provide information on the potential magnitude of this problem, we compared baseline characteristics of attriters (by wave 8) and non-attriters. The sample means were generally quite close. For instance, 24 percent of non-attriters classified their health in 1992 as excellent and 28 percent as very good, versus 23 and 27 percent of attriters; 53 percent of the former group are female compared to 52 percent of the latter. However, less educated individuals are slightly more likely than others to exit the sample. ${ }^{17}$

\subsection{Outcomes}

Our dependent variables include mortality and multiple measures of health status. To investigate potential mechanisms for changes in health, we also analyze out-of-pocket medical care expenditures, the use of several types of health care, and a set of lifestyle behaviors.

Mortality is, in some sense, the ultimate health outcome. Since the HRS respondents are aged 51 to 61 (and their spouses are 46 to 66 ) at baseline, and are followed for 14 years, deaths are common: around 20 percent of the non-attriter sample die prior to the 2006 interview. On the other hand, because some important health outcomes are unrelated or only weakly related to mortality, we also examine a variety of other indicators. The first of these is self-reported overall

\footnotetext{
${ }^{15}$ Birth years of the spouses range from 1907 to 1969.

${ }^{16}$ The results are not sensitive to this choice.

${ }^{17}$ Twenty-eight percent of attriters are high school dropouts and 13 percent are college graduates, compared to 24 and 17 percent of non-attriters.
} 
health. ${ }^{18}$ From the original categories of excellent, very good, good, fair and poor, we construct dichotomous variables for excellent and fair/poor health. Second, we measure limitations in activities of daily living (ADLs) or instrumental activities of daily living (IADLs). The binary ADL variable is set to one for persons reporting difficulty in: bathing, dressing, eating, moving from bed to chair or walking around. IADL equals one for individuals who have difficulty (without help): answering a phone, managing money, taking medicine, shopping or preparing meals. Our final proxy relates to mental health and is based on scores from the eight-item Center for Epidemiologic Studies (CESD) depression scale. ${ }^{19}$ Following previous research (Emptage et al., 2005; Doshi et al., 2008), we define persons with CESD scores of three or greater as “depressed”.

Since wealth might protect health or improve quality-of-life by allowing individuals to consume more medical care, we investigate how inheritances are related to out-of-pocket (OOP) medical expenditures, inpatient and outpatient treatments, nursing and home health care, doctor visits, prescribed medications, and dental care. OOP spending indicates the total amount paid for medical services since the last interview; the other variables are dichotomous indicators of use since that time. $^{20}$ Hospital and nursing home visits are coded as positive if there has been an overnight stay. Outpatient care refers to outpatient surgery (as distinguished from doctor visits) and home health care to visits by medically trained professionals such as nurses, nurse’s aides, physical/occupational therapists, chemotherapists or respiratory therapists. Doctor visits measure whether a respondent went to a physician at least once and dental care includes seeing a

\footnotetext{
${ }^{18}$ Self-reported health is predictive of health status and future mortality (e.g. Idler and Angel, 1990). There may be cultural differences in self-assessments of health (Jurges, 2008) but this should not be much of an issue for panel data exploiting within-person variations.

${ }^{19}$ CESD scores in waves 2 and later of the HRS range between zero and eight and are obtained by summing eight questions related to depression. These include both negative indicators (e.g. feelings of sadness, depression, and lonliness) and positive ones (e.g. feelings of happiness or life enjoyment). All questions are scored such that higher values are more indicative of depression. Tuvey (et al., 1999) provides discussion of the eight-item CESD scale. ${ }^{20}$ OOP expenditures refer to spending on hospital or nursing home stays; doctor, outpatient and dental visits; home health care and prescription drug use.
} 
dentist or obtaining dentures. Prescription use is based on whether the respondent regularly took prescription medications during the last two years.

Bequests may also change health-related lifestyles. We examine the effects on alcohol use, smoking, vigorous exercise and obesity. Drinking is modeled in several ways. First, we include a dichotomous indicator of whether the respondent consumed any alcohol during the last three months and a continuous measure of drinks per day conditional on use. ${ }^{21}$ Second, since the effects of recreational and heavy drinking could differ (with the former sometimes associated with health benefits), we analyze categorical variables measuring consumption of 1 to 7 or 1 to 14 drinks per week (light/moderate alcohol use) and greater than 14 drinks weekly (heavy consumption). ${ }^{22}$ We investigate tobacco use, through a binary variable set to one for persons smoking at the time of the interview, as well as physical activity using a dichotomous indicator of vigorous exercise occurring at least three times per week. Lastly, we consider excess body weight, which reflects the combined influences of physical activity and diet. Obesity is defined as body mass index (BMI) of 30 or higher, and class 2 obesity as BMI of 35 or more. ${ }^{23}$

\subsection{Explanatory Variables}

The key explanatory variables relate to inheritances. We delete from the analysis persons obtaining bequests prior to the initial interview, in 1992, and calculate the total inheritance amount received between the first interview and the current survey (whether from single or multiple bequests). Our main analysis uses two variables. The first indicates if any inheritance has been received; the second denotes bequests of $\$ 10,000$ or more. For brevity, we refer to the

\footnotetext{
${ }^{21}$ Drinks per day is calculated as the product of the number of weekly drinking days times the number of beverages consumed on these days, again measured over the last three months. This information is not provided for 1994 and observations for that year are excluded from this portion of the analysis.

${ }^{22}$ The reference group includes non-drinkers, as well as persons consuming other than the specified amounts.

${ }^{23} \mathrm{BMI}$ is based on self-reported height and weight. These are measured with error, generally leading to an understatement of BMI, but there is no reason these mistakes should be systematically related to inheritance receipt.
} 
latter as "large” inheritances, with those below $\$ 10,000$ sometimes called "small”. ${ }^{24}$ We also perform sensitivity analysis dividing inheritance amounts more finely (e.g. into five categories rather than two), varying the threshold between "large" and "small” bequests, or measuring inheritance size as a proportion of income rather than by an absolute dollar amount.

Supplementary regressors include demographic characteristics such as sex, age and agesquared, marital status, education and (the natural log of) household income, all measured at baseline. Most of these are standard and do not require explanation. Married and cohabiting individuals are separately classified, as are high school graduates and those with a GED. Household income refers to receipts by the husband and wife from earnings, veterans' benefits, retirement or pensions, annuities, IRA distributions, stocks and bonds, savings accounts, rental properties, investment trusts and other sources. Finally, to allow for the possibility that recent death of a parent affects the outcomes, we control for whether the respondent's mother or father (two dichotomous variables) died since the previous survey wave. ${ }^{25}$

Most models control include four dummy variables for self-assessed overall health (fair, good, very good or excellent, with poor health the reference category) at baseline (1992), dichotomous regressors for underweight, overweight, mild obesity or severe obesity (BMI ranges $\leq 18.5$, 25 to 29.9, 30 to 39.9, and $\geq 40$ ), as well as smoking status. Appendix Table A.1 provides summary statistics on these and other variables used in the analysis, as well as the outcomes.

We also estimated specifications with controls for parental education, ADLs, IADLs and alcohol use at baseline, since these might capture remaining sources of heterogeneity. The results were insensitive to their inclusion and these models are not reported below.

\footnotetext{
${ }^{24}$ Inheritances less than \$50,000, but with the exact amount not specified, are placed in the "large” category, introducing some possibility for error. The resulting bias is likely to be minor since this covers just 1.6 percent of inheritances and similar results are obtained when these individuals are dropped from the sample.

${ }^{25}$ These variables are set to zero and a missing value dummy variable set to one if information on parental death is unavailable.
} 


\section{ECONOMETRIC METHODS}

The question of interest is whether inheritance receipt causally affects health outcomes and inputs. Consider a general specification:

$$
Y_{i, t}=X_{i} b+\text { Any Inherit } t_{i, t} c+\mu_{i, t},
$$

where $Y_{i, t}$ is a health outcome for individual i at time t, Any Inherit $t_{i, t}$ indicates inheritance receipt by the current survey wave, $X_{i}$ is a vector of control variables measured at baseline (the 1992 interview), and $\mu_{i, t}$ is a regression disturbance term. The HRS surveys individuals at two-year intervals (from 1992 to 2006) and equation (1) allows even recently received inheritances to affect the outcomes. The results are generally insensitive to this assumption, as discussed below.

Our most important concern relates to the difficulty of adequately controlling for heterogeneity between persons who do and do not receive bequests. Observable characteristics available in the HRS suggest that inheritance receivers are more advantaged along a variety of dimensions: they are relatively educated and healthy at baseline (see Table 2). Failure to account for this heterogeneity will lead to erroneously favorable estimates of the health benefits of inheritances. We partially address this issue by controlling for demographic characteristics and health status at baseline. The latter should remove sources of confounding that affect health similarly in 1992 and in later years.

An additional innovation is that we focus on the incremental impact of large bequests, beyond those of inheritances likely to be too small to meaningfully affect health. Specifically, our main models take the form:

$$
Y_{i, t}=X_{i} b+\text { Any } \text { Inherit }_{i, t} c+\text { Inherit } \geq \$ 10,000_{i, t} d+\mu_{i, t},
$$

where Inherit $\geq \$ 10,000$ indicates receipt of inheritances of $\$ 10,000$ or more. Any Inherit and Inherit $\geq \$ 10,000$ are both set to one for persons obtaining "large" bequests, whereas only the 
former equals one (with Inherit $\geq \$ 10,000$ set to zero) for individuals receiving small (below $\$ 10,000)$ inheritances. $\hat{c}$ then provides the regression estimate of the "effect" of a small inheritance, which is assumed to reflect otherwise uncontrolled for heterogeneity, and $\hat{d}$ shows the additional (causal) impact of a large bequest. ${ }^{26}$ The key identifying assumptions are that inheritances below $\$ 10,000$ must be too small to materially affect health and that receivers of small and large inheritances have similar unobserved characteristics, after controlling for baseline demographics and health status. The first assumption seems quite plausible. Although we are less sure about the second supposition, any remaining omitted variables seem likely bias the estimates towards overstating the health benefits of inheritances since the observables suggest more favorable selection for larger inheritances (see Table 2), so that a finding of little or no benefit is informative.

Since there are up to seven observations per individual (covering the second through eight waves), we calculate robust standard errors, after clustering at the individual level.

\subsection{Mortality}

Inheritance receipt is likely to be mechanically correlated with death rates because early mortality precludes the future receipt of a bequest. Consider the example where inheritances have no effect on health and two individuals would both inherit in wave 5, conditional on living that long, but that one of them dies in wave 3 (before the bequest is received). Inheritances are then negatively associated with fatality rates - since the non-receiver does not live as long as the inheritor - but this reflects mortality selection rather than a causal effect.

To address this issue, we estimate a discrete time logit hazard model specified by:

$$
M_{i, t}=\exp \left(Z_{i, t} \beta\right) /\left(1+\exp \left(Z_{i, t} \beta\right)\right)
$$

\footnotetext{
${ }^{26}$ To see this, assume that $Y_{i, t}=X_{i} b+$ Inherit $<\$ 10,000_{i, t-1} c^{\prime}+$ Inherit $\geq \$ 10,000_{i, t-1} d^{\prime}+\mu_{i, t}$, where Inherit $<\$ 10,000$ is a binary variable indicating receipt of a "small" inheritance. Since Inherit equals one if either Inherit $<\$ 10,000$ or Inherit $\geq \$ 10,000$ is one, this can be rewritten as: $Y_{i, t}=X_{i} b+$ Inherit $_{i, t-1} c^{\prime}+\operatorname{Inherit} \geq \$ 10,000_{, t-1}\left(d^{\prime}-c^{\prime}\right)$ $+\mu_{i, t}$. Therefore, in equation (1'), $c=c^{\prime}$ and $d=d^{\prime}-c^{\prime}$.
} 
where $\mathrm{M}_{i, t}$ is the mortality hazard rate, the probability of dying between wave $t-1$ and $t$ conditional on being alive at $t-1$, and

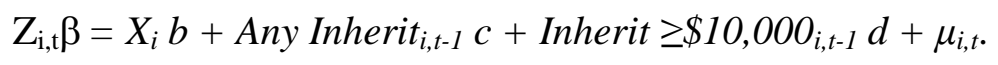

Since inheritance receipt is measured at $t-1$, and the hazard rate is conditioned on living at least that long, these estimates are not contaminated by the mortality selection. The model also easily accounts for censoring due to attrition or survival through the end of the analysis period.

Notice that since (2) can be rewritten as:

$$
\ln \left[M_{i, t} /\left(1-M_{i, t}\right)\right]=\mathrm{Z}_{\mathrm{i}, \mathrm{f}} \beta
$$

and mortality hazard rates are small, averaging $.029,\left(1-\mathrm{M}_{\mathrm{i}, \mathrm{t}}\right) \approx 1$. Thus, the log mortality rate is approximately linear in the covariates and marginal effects are closely estimated by $\exp (\hat{\beta})-1$.

\subsection{Other Outcomes}

Most dependent variables, other than mortality, are dichotomous. The predicted effects of inheritances on these outcomes are estimated using linear probability models (LPM) defined by equation (1'). ${ }^{27}$ We again have multiple observations for most individuals, but with missing values where death or attrition precedes the interview date.

Out-of-pocket medical spending and alcohol use are analyzed using a two-part model that separately estimates the determinants of positive use and the amounts conditional on such use (Duan, Manning, Morris, and Newhouse, 1983; Madden, 2008). The participation equation is estimated as an LPM model equivalent to (1'). The conditional use specification, is semi-log, taking the form:

$$
\operatorname{Ln}\left(Y_{i, t} \mid Y_{i, t}>0\right)=X_{i} b+\text { Any Inherit }{ }_{i, t} c+\text { Inherit } \geq \$ 10,000_{i, t} d+\mu_{i, t},
$$

with the impact of a large inheritance shock estimated as $\exp (\hat{d})-1$.

\footnotetext{
${ }^{27}$ We also estimated some specifications as probit models. The resulting marginal effects were close to those from corresponding LPM estimates.
} 


\section{RESULTS}

\subsection{Mortality Rates}

The predicted effect of inheritances on mortality hazard rates is displayed in Table 3. As discussed, the coefficient on Inherit $\geq \$ 10,000$ provides our best estimate of the true wealth effect, with that on Any Inherit indicating the role of confounding factors remaining after inclusion of the supplementary regressors. The estimated inheritance effects will still be biased if there are systematic differences in the unobserved characteristics of persons obtaining large and small inheritances, holding other explanatory variables constant. Such confounding is likely to be particularly severe in models with parsimonious controls and so we anticipate that the large inheritance coefficient will change as we move from less to more fully specified models.

Column (1) of Table 3 holds constant only the two inheritance variables. The large negative coefficient on Any Inherit provides evidence of remaining heterogeneity, as anticipated since inheritance receivers are favorably selected and this specification contains no other controls. Large bequests are associated with a substantial but imprecisely estimated (and insignificant) 13 percent reduction in mortality hazard rates.

The beneficial effect of large inheritances rises, to an estimated 17 percent reduction in the mortality hazard, when age and sex are controlled for (see column 2). This occurs because age is positively correlated with both inheritances and death. By contrast, the coefficient is attenuated when adding controls for other demographic characteristics, recent parental death and baseline health status (models 3 and 4). In the most comprehensive specification (column 5), which also holds constant baseline smoking and body weight, large inheritances are correlated with a statistically insignificant 2.8 percent increase in the mortality hazard. ${ }^{28}$ Thus, there is no evidence that large inheritances substantially reduce deaths, after accounting for important

\footnotetext{
${ }^{28}$ The sign of the large bequest parameter estimate switches from negative to positive when moving from column (4) to (5) because smokers have high mortality rates and probabilities of receiving small inheritances but relatively infrequently obtain large ones.
} 
sources of heterogeneity, although large standard errors imply that all such conclusions are tentative. $^{29}$

\subsection{Health Indicators}

The data hint at the possibility that substantial bequests lead to improvements in the health-related quality of life. This can be seen in Table 4, which summarizes results for the five health indicators. Here, and throughout the remaining analysis, we report findings for models corresponding to column (5) of Table 3. The point estimates suggest that inheritances of $\$ 10,000$ or more are associated with an increased likelihood of “excellent” overall health and lower rates of ADLs, IADLs and depression; the parameter estimate for fair/poor health is zero. Three of the predicted changes (for excellent self-assessed health, ADLs and depression) are 5 to 8 percent as large as the dependent variable mean, while the coefficient on IADLs corresponds to nearly 20 percent of baseline. ${ }^{30}$

However, there are at least two reasons to be cautious about placing a strong causal interpretation on these results. First, the standard errors are large, such that we never come close to rejecting the hypothesis of no health effect at conventional levels of statistical significance.

Second, the issue of uncontrolled for heterogeneity remains a concern, even in our most comprehensive models. Specifically, the magnitude of the large inheritance coefficient declines as we more fully account for observables, leaving the possibility that the addition of further controls would move the point estimate even closer to zero. ${ }^{31}$

\footnotetext{
${ }^{29}$ Coefficients on the supplementary covariates are generally in the expected directions. Mortality hazard rates are relatively high for males, older sample members, smokers, those in poor initial health, and underweight or severely obese individuals. Education and income do not have strong predicted effects in the most comprehensive model, largely because baseline health - which is influenced by income and education - has already been controlled for. The coefficient on Any Inherit is generally attenuated by including additional covariates, as expected since it captures the effects of omitted variables.

${ }^{30}$ The parameter estimates for Any Inherit again generally point to favorable inheritance selection (although most coefficients are not statistically significant) and the supplementary covariates usually have the expected signs.

${ }^{31}$ For example, in specifications corresponding to columns (1) and (3) of Table 3, the large inheritance coefficient is 0.0500 and 0.0295 for excellent health, -0.0270 and -0.0112 for ADLs, -0.0198 and -0.0117 for IADLs and -0.0517 and -0.0213 for depression.
} 


\subsection{Medical Care}

Positive wealth shocks are predicted to increase personal (out-of-pocket) expenditures on medical care, if the latter is a normal good. Table 5 confirms this expectation. Large inheritances raise the probability of positive OOP spending, but the effect is small and statistically insignificant because the vast majority (over 90 percent) of the sample has some expenditure (column 1). The results in column (2) are more dramatic, showing that such bequests increase expected OOP spending, conditional on positive amounts, by a highly significant 23.3 percent.

The remainder of Table 5 indicates that inheritances are associated with higher use of the seven specific types of health services examined, although many estimates are statistically insignificant. Most notably, bequests of $\$ 10,000$ or more are predicted to raise the probability of dental care by 8.7 percentage points, on a base of 64 percent, and home health care by 1.2 points on a base of 4.4 percent. Both of these are likely to have a large discretionary component that is plausibly affected by bequest-related wealth shocks. By contrast, inpatient hospitalizations are likely to be less sensitive to economic circumstances and so it is no surprise that the inheritance effects are small (0.7 points on a base of 22 percent) and insignificant. Growth in the predicted probability of doctor visits or prescription drug use is also tiny -0.3 and 0.4 percentage points on sample averages of 93.0 and 72.4 percent - probably because these are so common (and we do not measure changes at the intensive margin), whereas the expected rise in outpatient and nursing home care is sizeable ( 0.7 and 0.2 percentage points on a base of 19.5 and 1.3 percent) although imprecisely estimated.

These results suggest that inheritance receivers use some of their new wealth to purchase of medical care, particularly those types with a substantial discretionary component.

\subsection{Health Behaviors}


Table 6 investigates how inheritance receipt affects alcohol use. Large bequests predict a statistically significant 10 percentage point increase in the probability of drinking (on a base of 51 percent), with a significant 11 percent rise in consumption conditional on some use. The health effects of this change are not transparent, since light drinking may protect from some health problems (Reynolds et al., 2003), whereas heavy use is likely to be harmful. However, the remainder of the table shows that recreational drinking grows the most: the predicted probability of consuming 1 to 7 or 1 to 14 drinks per week rises 6.3 and 10.2 percentage points, compared to a 1.7 point growth in consumption of more than 14 alcoholic beverages weekly. ${ }^{32}$

The findings for the other behaviors - exercise, smoking and obesity - are ambiguous but most often suggest that inheritance shocks change lifestyles in ways likely to improve health. Specifically, as shown in Table 7, bequests over $\$ 10,000$ have little impact on exercise or smoking but predict substantial, although imprecisely estimated, decreases in obesity and severe obesity (2.9 and 1.2 percentage points on a base of 25.8 and 7.6percent).

\subsection{Gender Differences}

We investigated whether bequests affect men and women differently. Although large standard errors make it difficult to draw firm conclusions, the results (not shown) raise the possibility of more favorable consequences for males. For instance, large inheritances predict a sizeable (but statistically insignificant) 43 percent increase in the mortality hazard rate of women versus a 16 percent reduction for men. The point estimates further suggest a substantial fall in ADLs, IADLs and depression for males (with the last two being statistically significant), compared to increases in all three outcomes for females. Positive wealth shocks are estimated to raise the overall use of medical care for both men and women, with larger effects for the females. For example, conditional on positive amounts, inheritances of $\$ 10,000$ or more were associated

\footnotetext{
${ }^{32}$ Although the estimated rise in the probability of drinking more than 14 drinks per drink is large relative to the (small) base level, it is the absolute not relative increases in the probabilities of light versus heavy drinking that are important for evaluating how changes in alcohol consumption affect average health.
} 
with a 30.1 percent growth in OOP spending for women versus 15.5 percent for men. Finally, sizable inheritances increase predicted drinking for both sexes, with larger growth in light consumption for women than men. There were no consistent gender differences for exercise, smoking or body weight, and none of these inheritance effects approached statistical significance.

\section{DISCUSSION}

Our analysis suggests that the positive wealth shocks resulting from substantial inheritances fail to reduce mortality, and might be associated with increased death rates. Nor is there convincing evidence of improvements in other measures of health. This is not a complete surprise since previous quasi-experimental analyses obtained mixed results, often finding that positive income or wealth shocks had no impact or adverse effects on health. Nevertheless, economic theory predicts beneficial consequences and our efforts to provide mechanisms for the observed effects are not particularly successful. Most potential moderating factors examined seem likely to improve health (i.e. greater use of medical care, increases in light alcohol and decreased obesity).

We tested the robustness of our findings to a variety of alternative specifications. To allow for the possibility that inheritances only gradually improve health, we estimated models examining how self-assessed health was related to inheritances received 2, 4, 6, 8, 10, 12 or 14 years earlier, among persons remaining in the sample at the wave 8 interview. These failed to show any clear pattern and, in particular, did not provide consistent evidence of stronger health effects for inheritances received further in the past.

We investigated sensitivity of the results to use of the $\$ 10,000$ threshold defining "large" inheritances through specifications where the cut point was $\$ 3,000, \$ 5,000 \$ 7,000$ or $\$ 20,000$. Qualitatively similar results were almost always obtained. The one exception was that large inheritances predicted implausibly big (but still insignificant) increases in mortality using the 
$\$ 3,000$ and $\$ 5,000$ boundaries. ${ }^{33}$ We cannot explain these last results (indicating strong negative wealth effects on health) but note that they are obtained in specifications where very few persons were classified as receiving "small” inheritances (e.g. less than one percent of observations using the $\$ 3,000$ standard).

Positive wealth shocks of a given size might have different effects on poor than wealthy individuals, since the change in relative economic well-being is larger for the former group. We addressed this through models measuring inheritance size as a proportion of baseline household incomes (with the analysis limited to persons not retired in 1992). Although the results were somewhat sensitive to the threshold dividing "large" and "small" inheritances, there was never consistent evidence of large and statistically significant health effects. ${ }^{34}$

Inheritances might have few effects on health because they are fully anticipated and so do not represent true shocks. We view this as unlikely, since neither the timing nor amount of bequests are known in advance, and many individuals might be reluctant to alter their spending before inheritances are actually received. ${ }^{35}$ Nevertheless, to investigate this issue, we defined inheritances as “expected” for individuals reporting (in 1994) that their subjective probability of obtaining a bequest during the next 10 years was at least 50 on a 100 point scale (and unexpected otherwise). We then investigated the effects on health status and medical care utilization in 2006. These revealed qualitatively similar predicted effects of expected and unexpected inheritances

\footnotetext{
${ }^{33}$ Large inheritances were predicted to increase mortality hazards by approximately 27 and 24 percent in these cases. ${ }^{34}$ For instance, results similar to those above were obtained when setting the inheritance threshold at 10 percent of annual (baseline) income. Conversely, using an 18 percent threshold, large bequests predicted much smaller (statistically insignificant) increases in out-of-pocket health care spending or in the use of specific medical services. ${ }^{35}$ There is direct evidence that individuals have limited ability to predict the future receipt of inheritances. Just 51 percent of respondents stating, in 1994, that they had a 100 percent probability of inheriting during the next ten years actually obtained a bequest by 2006 (conditional on surviving until then). At the other extreme, most (68 percent) of the HRS sample claimed to have no possibility of obtaining an inheritance but 12 percent of this group actually received one by 2006.
} 
for most outcomes, suggesting that bequest expectations are inaccurate, individuals do not treat expected inheritances like other sources of wealth, or that health is unaffected by them. ${ }^{36}$

The main results were robust to several other specification checks. We examined but uncovered no consistent evidence of uncontrolled for differences in the health trends of inheritance receivers and non-receivers. ${ }^{37}$ Some specifications divided large inheritances into four separate categories $(\$ 10,001-\$ 25,000, \$ 25,001-\$ 100,000, \$ 100,001-\$ 250,000,>\$ 250,000)$. We also experimented with fixed-effect estimates as an alternative method of controlling for heterogeneity. Our main conclusions remained unchanged.

We are left to conclude that the wealth shocks resulting from large bequests have negligible impacts on mortality, although with some possibility of improvements in other measures of health. The main specifications indicate that out-of-pocket health expenditures and the use of medical services, particularly discretionary components such as dental or home health care, do increase. Alcohol consumption also rises, probably with beneficial effects on health, since the change is dominated by growth in light rather than heavy drinking. The data also suggest, although not conclusively, that obesity and severe obesity decline, which should yield health benefits.

Many of our estimates are large in magnitude but imprecisely estimated, raising the issue of limited statistical power. However, it is noteworthy that we did find substantial and significant effects for out-of-pocket medical spending and some types of health care (dental visits and home health care) likely to have a strong discretionary component. The average

\footnotetext{
${ }^{36}$ For instance, expected and unexpected inheritances raise OOP health care spending and drinking by similar amounts. However, unexpected bequests may have larger positive (negative) effects on dental visits (obesity prevalence) and, if anything, more detrimental consequences for self-assessed health.

${ }^{37}$ To accomplish this, we selected individuals surviving through the eighth survey wave who had not received an inheritance by wave four (1998). We then examined, but found no evidence of, differences in changes in selfassessed health between waves one and four (prior to potential inheritance receipt), as a function of whether or not a bequest was obtained between waves four and eight. Specifically, the health of large inheritance receivers deteriorated slightly (between waves one and four) relative to non-receivers but this was entirely due to their superior health at baseline. Controlling for health in 1992, the relative health of receivers trended slightly upwards between waves one and four. None of these differences approached statistical significance.
} 
sample member spends about $\$ 1,250$ per year out-of-pocket on medical care and a large inheritance is predicted to raise this by around $\$ 300$. Such an increase might not be sufficient to have large effects on overall health or mortality but, particularly when used for purposes such as dental care, might improve quality-of-life in ways that we poorly measure.

Even if the health is unrelated to income or wealth for the HRS age group, the latter could be important earlier in the lifecycle. To shed light on this, we separately examined results for persons below age 65 versus 65 and over. Inheritances might have weaker health benefits for the older group since virtually all of them are covered by Medicare, whereas their younger counterparts generally are not. Consistent with this, substantial bequests were associated with larger reductions in deaths and bigger improvements in all measures of health for those under 65, although the estimates were again imprecise. Interestingly, out-of-pocket health spending increased by similar amounts for both age groups, in part because seniors had large increases in the types of medical care (such as dental visits) not covered under Medicare. 


\section{References}

Adams, Peter, Michael D. Hurd, Daniel McFadden, Angela Merrill, and Tiago Ribeiro. 2003. "Healthy, Wealthy and Wise? Tests for Direct Causal Paths Between Health and Socioeconomic Status” Journal of Econometrics 112, 3-56.

Adda, Jérôme, James Banks, and Hans-Martin von Gaudecker. Forthcoming. "The Impact of Income Shocks on Health: Evidence from Cohort Data” Journal of the European Economic Association.

Case, A. D. Lubotsky, and C. Paxson, 2002. "Economic Status and Health in Childhood: The Origins of the Gradient” American Economic Review, 92(5), December, 1308-1334.

Case, Anne. 2004. "Does Money Protect Health Status? Evidence from South African Pensions” in David Wise (ed.) Perspectives in the Economics of Aging. Chicago: University of Chicago Press, 287-311.

Doshi, Jalpa A., Liyi Cen and Daniel Polsky. 2008. "Depression and Retirement in Late MiddleAged U.S. Workers” Health Services Research 43(2), April, 693-713.

Deaton, Angus S. and Christina H. Paxson. 1998 “Aging and Inequality in Income and Health” American Economic Review 88(2), May, 248-253.

Duan, N., W. Manning, C. Morris and J. Newhouse. 1983. “A Comparison of Alternative Models for the Demand for Medical Care" Journal of Business Economics and Statistics 1(2), April, 115-126.

Emptage, Nicholas P., Roland Sturm and Rebecca L. Robinson. 2005. "Depression and Comorbid Pain as Predictors of Disability, Employment Insurance Status, and Health Care Costs” Psychiatric Services 56(4), April, 468-474.

Ettner, Susan L. 1996. “New Evidence on the Relationship Between Income and Health” Journal of Health Economics 15(1), February, 67-85.

Feinstein, Jonathan S. 1993. "The Relationship Between Socioeconomic Status and Health” The Milbank Quarterly 71(2), 279-322.

Frijters, Paul, John P. Haisken-DeNew, and Michael Shields. 2005. "The Causal Effect of Income on Health: Evidence from German Unification” Journal of Health Economics 24(5), 997-1017.

Fuchs, Victor R. 1982. "Time Preferences and Health: An Exploratory Study" in Victor R. Fuchs (Ed.), Economic Aspects of Health. Chicago: University of Chicago Press.

Kitagawa, Evelyn and Philip Hauser. 1973. Differential Mortality in the United States: A study in Socioeconomic Epidemiology. Cambridge, MA: Harvard University Press.

Gardner, Jonathan and Andrew J. Oswald. 2004. "How is Mortality Affected by Money, Marriage and Stress” Journal of Health Economics 23, 1181-1207. 
Gardner, Jonathan and Andrew J. Oswald. 2007. "Money and Mental Wellbeing: A Longitudinal Study of Medium -Sized Lottery Wins” Journal of Health Economics 26(1), January, 49-60.

Gist, John and Carlos Figueiredo. 2006. "In Their Dreams: What Will Boomers Inherit” AARP Public Policy Institute Data Digest No. 139, May.

Grossman, Michael. 1972. “On the Concept of Health Capital and the Demand for Health” Journal of Political Economy 80(2), 233-55.

Idler, Ellen L. and Ronald J. Angel. 1990. "Self-rated Health and Mortality in the NHANES-I Epidemiologic Follow-up Study” American Journal of Public Health 80(4), April, 446-452.

Jürges, Hendrik. 2007. "True Health vs. Response Styles: Exploring Cross-country Differences in Self-Reported Health," Health Economics 16(2), 163-178.

Kaplan, H.R. 1978. Lottery Winners: How They Won and How Winning Changed Their Lives. New York: Harper and Row.

Lindahl, Marting. 2005. "Estimating the Effect of Income and Health and Mortality: Using Lottery Prizes as an Exogenous Source of Variation in Income” Journal of Human Resources 40(1), 144-168.

Madden, David. 2008. "Sample Selection Versus Two-part Models Revisited: The Case of Female Smoking and Drinking” Journal of Health Economics, 27(2): 300-307.

Marmot, M., M. J. Shipley, and G. Rose. 1984. "Inequalities in Death - Specific Explanations of a General Pattern" Lancet 1(8384), May 5, 1003-1006

Marmot, M.G, G.Davey Smith, Stephen Stansfeld, Chandra Patel, Fionna North, Jenny Head, Ian White, Eric Brunner, and Amanda Feeny. 1991. "Health Inequalities Among British Civil Servants: The Whitehall II Study” Lancet 337(8754), June 8, 1387-93.

Meer, Jonathan, Douglas L. Miller, and Harvey Rosen. 2003. "Exploring the Health-Wealth Nexus” Journal of Health Economics 22(5), September, 713-720.

Michaud, Pierre-Carl and Arthur van Soest. 2008. "Health and Wealth of Elderly Couples: Causality Tests Using Dynamic Data and Panel Models” Journal of Health Economics 27(5), September, 1312-1325.

RAND Corporation. 2008. RAND HRS Data Documentation, Version H. Rand Center for the Study of Aging (www.rand.org/labor/aging), February.

Reynolds Kristi, Brian L. Lewis, Nolen John David L. Nolen, Gregory L. Kinney, Bhavani Sathya, Jiang He. 2003. "Alcohol Consumption and Risk of Stroke: a Meta-analysis” Journal of American Medical Association 289(5), February 5, 579-88.

Ruhm, Christopher J. 2000. “Are Recessions Good For Your Health?” Quarterly Journal of Economics 115(2), May, 617-650. 
Ruhm, Christopher J. 2005. "Healthy Living in Hard Times” Journal of Health Economics 24(2), March, 341-63.

Ruhm, Christopher J. 2007. “A Healthy Economy Can Break Your Heart” Demography 44(4), November, 829-848.

Smith, James P. 1999. "Healthy Bodies and Thick Wallets: The Dual Relationship Between Health and Economic Status” Journal of Economic Perspectives 13(2), 145-66.

Smith, James P. 2004. “Unraveling the SES: Health Connection” Population Development and Review 30(supplement), 108-132.

Snyder, Stephen E. and William N. Evans. 2006. “The Effect of Income on Mortality”: Evidence from the Social Security Notch” Review of Economics and Statistics 88(3), August, 482-495.

Turvey, Carolyn L., Robert B. Wallace and Regula Herzog. 1999. “A Revised CES-D Measure of Depressive Symptoms and a DSM-Based Measure of Major Depressive Episodes in the Elderly” International Psychogeriatrics, 11(2), June, 139-148.

van den Berg, Gerard J., Maarten. Lindeboom, and France. Portrait. 2006. “Economic Conditions Early in Life and Individual Mortality” American Economic Review, 96(1), March, 290-302.

Wadsworth, M.E.J. and D.J.L. Kuh. 1997. "Childhood influences on adult health: a review of recent work from the British 1946 national birth cohort study, the MRC National Survey of Health and Development” Paediatric and Perinatal Epidemiology 11(1), January, 2-20. 
Table 1. Probability of Receiving Inheritance and Size of Inheritance

\begin{tabular}{lcccc}
\hline \hline & Whites & Blacks & $\begin{array}{c}\text { White } \\
\text { Females }\end{array}$ & $\begin{array}{c}\text { White } \\
\text { Males }\end{array}$ \\
\hline$\%$ Received Inheritance by Wave 8 & 23.50 & 5.72 & 23.88 & 23.08 \\
$\% \geq \$ 10,000$ & 17.00 & 3.50 & 16.96 & 17.05 \\
$\%<\$ 10,000$ & 4.33 & 1.35 & 4.64 & 3.99 \\
$\%$ Missing Inheritance Amount & 2.15 & 0.87 & 2.28 & 1.99 \\
\hline Average Cumulative Inheritance Amount by Wave $8(2002$ dollars $)$ & & \\
Full sample & 20,449 & 2,201 & 19,955 & 21,002 \\
Received Inheritance & 87,015 & 38,463 & 83,577 & 91,010 \\
Received Inheritance $\geq \$ 10,000$ & 113,909 & 61,230 & 116,522 & 110,990 \\
Received Inheritance of $<\$ 10,000$ & 4,288 & 4,426 & 4,256 & 4,331 \\
$N$ & 5217 & 1258 & 2760 & 2457 \\
\hline
\end{tabular}

Note: Data are from the Health and Retirement Survey and refer to respondents who had not received an inheritance prior to 1992 and lived through the wave eight (2006) interview. 
Table 2. Selected Demographic Variable Means By Inheritance Receipt and Amount

\begin{tabular}{|c|c|c|c|}
\hline Baseline Control Variables & No Inheritance & $\begin{array}{c}\text { Inheritance } \\
<\$ 10,000\end{array}$ & $\begin{array}{l}\text { Inheritance } \\
\geq \$ 10,000\end{array}$ \\
\hline Female & .5264 & .5664 & .5276 \\
\hline \multicolumn{4}{|l|}{ Education } \\
\hline High School Dropout & .2869 & .1460 & .0811 \\
\hline GED & .0619 & .0664 & .0361 \\
\hline High School Graduate & .3390 & .4159 & .3382 \\
\hline Some College & .1741 & .2212 & .2593 \\
\hline College Graduate & .1381 & .1504 & .2852 \\
\hline \multicolumn{4}{|l|}{ Self-Assessed Health Status } \\
\hline Excellent & .2122 & .2300 & .3439 \\
\hline Very Good & .2674 & .3142 & .3315 \\
\hline Good & .2791 & .3009 & .2345 \\
\hline Fair & .1456 & .1283 & .0710 \\
\hline Poor & .0958 & .0266 & .0192 \\
\hline Smoker* & .2641 & .2876 & .1849 \\
\hline$N$ & 3991 & 226 & 887 \\
\hline
\end{tabular}

Note: Sample is limited to whites providing data through 2006. All baseline variables are measured in 1992, except for smoking, where the data were first collected in 1994. Subsamples are stratified according to inheritance receipt and amount through the eighth survey wave (in 2006). 
Table 3. Predicted Effect of Inheritance Receipt on Mortality

\begin{tabular}{|c|c|c|c|c|c|}
\hline & $(1)$ & (2) & (3) & $(4)$ & $(5)$ \\
\hline Inheritance $\geq \$ 10,000$ & $\begin{array}{l}-0.1350 \\
(0.2478)\end{array}$ & $\begin{array}{l}-0.1816 \\
(0.2479)\end{array}$ & $\begin{array}{l}-0.0866 \\
(0.2497)\end{array}$ & $\begin{array}{l}-0.0266 \\
(0.2534)\end{array}$ & $\begin{array}{c}0.0278 \\
(0.2543)\end{array}$ \\
\hline Any Inheritance & $\begin{array}{c}-0.2962 \\
(0.2177)\end{array}$ & $\begin{array}{c}-0.2222 \\
(0.2178)\end{array}$ & $\begin{array}{c}-0.1909 \\
(0.2199)\end{array}$ & $\begin{array}{c}-0.1503 \\
(0.2246)\end{array}$ & $\begin{array}{c}-0.1913 \\
(0.2251)\end{array}$ \\
\hline Female & & $\begin{array}{c}-0.4677^{\star \star \star} \\
(0.0714)\end{array}$ & $\begin{array}{c}-0.5806^{\star * *} \\
(0.0744)\end{array}$ & $\begin{array}{c}-0.6575^{\star * *} \\
(0.0772)\end{array}$ & $\begin{array}{c}-0.5899 * \star \star \\
(0.0776)\end{array}$ \\
\hline Age at survey wave & & $\begin{array}{l}-0.0429 \\
(0.1240)\end{array}$ & $\begin{array}{c}-0.1156 \\
(0.1263)\end{array}$ & $\begin{array}{c}-0.2046 \\
(0.1271)\end{array}$ & $\begin{array}{l}-0.1940 \\
(0.1281)\end{array}$ \\
\hline Age Squared & & $\begin{array}{c}0.0968 \\
(0.0938)\end{array}$ & $\begin{array}{c}0.1489 \\
(0.0955)\end{array}$ & $\begin{array}{l}0.2084 \text { ** } \\
(0.0964)\end{array}$ & $\begin{array}{l}0.2086^{* *} \\
(0.0971)\end{array}$ \\
\hline Mother Died Since Last Wave & & & $\begin{array}{c}0.1317 \\
(0.1539)\end{array}$ & $\begin{array}{c}0.1577 \\
(0.1553)\end{array}$ & $\begin{array}{c}0.1787 \\
(0.1552)\end{array}$ \\
\hline Father Died Since Last Wave & & & $\begin{array}{l}-0.4556 \\
(0.2944)\end{array}$ & $\begin{array}{l}-0.4345 \\
(0.2936)\end{array}$ & $\begin{array}{l}-0.4089 \\
(0.2916)\end{array}$ \\
\hline Cohabits & & & $\begin{array}{l}-0.3198 \\
(0.4264)\end{array}$ & $\begin{array}{l}-0.2896 \\
(0.4057)\end{array}$ & $\begin{array}{l}-0.3066 \\
(0.3931)\end{array}$ \\
\hline Separated/Divorced & & & $\begin{array}{c}0.3714 \\
(0.3473)\end{array}$ & $\begin{array}{c}0.3182 \\
(0.3493)\end{array}$ & $\begin{array}{c}0.2994 \\
(0.3470)\end{array}$ \\
\hline Widowed & & & $\begin{array}{c}0.0295 \\
(0.2444)\end{array}$ & $\begin{array}{c}-0.0542 \\
(0.2560)\end{array}$ & $\begin{array}{l}-0.1435 \\
(0.2575)\end{array}$ \\
\hline Never Married & & & $\begin{array}{c}0.4281^{\star \star \star} \\
(0.1067)\end{array}$ & $\begin{array}{l}0.2050^{\star} \\
(0.1128)\end{array}$ & $\begin{array}{c}0.1040 \\
(0.1145)\end{array}$ \\
\hline Less than High School & & & $\begin{array}{c}0.5084^{\star \star \star} \\
(0.1487)\end{array}$ & $\begin{array}{l}0.3318^{\star \star} \\
(0.1507)\end{array}$ & $\begin{array}{c}0.2109 \\
(0.1568)\end{array}$ \\
\hline GED & & & $\begin{array}{c}0.2042 \\
(0.2257)\end{array}$ & $\begin{array}{l}-0.0160 \\
(0.2252)\end{array}$ & $\begin{array}{c}0.0640 \\
(0.2157)\end{array}$ \\
\hline Some College & & & $\begin{array}{c}0.3244 * * * \\
(0.0873)\end{array}$ & $\begin{array}{c}0.0187 \\
(0.0914)\end{array}$ & $\begin{array}{l}-0.0218 \\
(0.0917)\end{array}$ \\
\hline College Graduate & & & $\begin{array}{c}0.0289 \\
(0.1568)\end{array}$ & $\begin{array}{l}-0.0563 \\
(0.1571)\end{array}$ & $\begin{array}{l}-0.0663 \\
(0.1574)\end{array}$ \\
\hline Log of Household Income & & & & $\begin{array}{c}0.0953 \\
(0.1014)\end{array}$ & $\begin{array}{c}0.1051 \\
(0.1030)\end{array}$ \\
\hline Very Good Health & & & & $\begin{array}{c}-0.1275 \\
(0.1195)\end{array}$ & $\begin{array}{l}-0.0154 \\
(0.1199)\end{array}$ \\
\hline Good Health & & & & $\begin{array}{l}-0.0369^{*} \\
(0.0197)\end{array}$ & $\begin{array}{l}-0.0340 \\
(0.0210)\end{array}$ \\
\hline Fair Health & & & & $\begin{array}{c}0.4725^{\star \star \star} \\
(0.1302)\end{array}$ & $\begin{array}{c}0.4209 * \star \star \\
(0.1303)\end{array}$ \\
\hline Poor Health & & & & $\begin{array}{c}0.8661^{\star \star \star} \\
(0.1246)\end{array}$ & $\begin{array}{c}0.7889 * \star \star \\
(0.1244)\end{array}$ \\
\hline Smoker & & & & & $\begin{array}{c}1.3916 * \star \star \\
(0.1373)\end{array}$ \\
\hline
\end{tabular}

Note: Robust standard errors, clustered by individual, are in parentheses. Table shows results of discrete time hazard models, with sample weights incorporated $(n=31,002) ;{ }^{*}=$ significant at $10 \%,{ }^{* *}=$ significant at $5 \%$; ${ }^{\star \star \star}=$ significant at $1 \%$ level. All supplementary regressors, except parental death, are measured at baseline (in 1992). Reference group includes high school graduates in excellent health (in 1992). Wave fixed effects are included in all regressions. Models (3) through (5) also include controls for missing values of parental death (since the last wave), and specification (5) also contains covariates for BMI in the ranges: $\leq 18.5,25$ to $29.9,30$ to 39.9 , and $\geq 40$. The mean between survey wave mortality hazard rate is $2.9 \%$. 
Table 4. Predicted Effect of Inheritance Receipt on Health Outcomes

\begin{tabular}{lccccc}
\hline \hline & $\begin{array}{c}\text { Fair/Poor } \\
\text { Health } \\
(1)\end{array}$ & $\begin{array}{c}\text { Excellent } \\
\text { Health } \\
(2)\end{array}$ & ADL & IADL & Depressed \\
\cline { 2 - 6 } & 0.0001 & 0.0103 & -0.0065 & -0.0100 & -0.0139 \\
Inheritance $\geq \$ 10,000$ & $(0.0169)$ & $(0.0165)$ & $(0.0132)$ & $(0.0114)$ & $(0.0184)$ \\
Any Inheritance & -0.0224 & 0.0023 & -0.0034 & 0.0071 & 0.0037 \\
Dependent Variable Mean & $(0.0152)$ & $(0.0144)$ & $(0.0119)$ & $(0.0107)$ & $(0.0171)$ \\
\hline
\end{tabular}

Note: Robust standard errors, clustered by individual, are in parentheses. Table shows results of linear probability models, with sample weights incorporated; * = significant at $10 \%$ level. The sample size is 36,618 , except for columns (3), (4) and (5), where it is $36,621,36,615$ and 34,343 . The estimates also control for the same supplementary covariates as in model (5) of Table 3. 
Table 5. Predicted Effect of Inheritance Receipt on Medical Care and Expenditures

\begin{tabular}{|c|c|c|c|c|c|c|c|c|c|}
\hline & $\begin{array}{c}\text { Positive } \\
\text { OOP } \\
(1)\end{array}$ & $\begin{array}{c}\log (\mathrm{OOP}) \\
\text { If }>0 \\
(2)\end{array}$ & $\begin{array}{c}\text { Visited } \\
\text { Dentist } \\
(3)\end{array}$ & $\begin{array}{c}\text { Prescrip- } \\
\text { tion Use } \\
(4)\end{array}$ & $\begin{array}{c}\text { Outpatient } \\
\text { Care } \\
(5)\end{array}$ & $\begin{array}{c}\text { Nursing } \\
\text { Home } \\
(6)\end{array}$ & $\begin{array}{c}\text { Home } \\
\text { Health } \\
\text { Care } \\
(7)\end{array}$ & $\begin{array}{c}\text { Visited } \\
\text { Doctor } \\
(8)\end{array}$ & $\begin{array}{c}\text { Hospital } \\
\text { Episode } \\
(9)\end{array}$ \\
\hline Inheritance $\geq \$ 10,000$ & $\begin{array}{c}0.0134 \\
(0.0117)\end{array}$ & $\begin{array}{c}0.2100^{\star \star \star} \\
(0.0724)\end{array}$ & $\begin{array}{c}0.0866^{\star \star \star} \\
(0.0261)\end{array}$ & $\begin{array}{c}0.0357 \\
(0.0238)\end{array}$ & $\begin{array}{c}0.0065 \\
(0.0164)\end{array}$ & $\begin{array}{c}0.0020 \\
(0.0042)\end{array}$ & $\begin{array}{l}0.0120 * \\
(0.0069)\end{array}$ & $\begin{array}{c}0.0034 \\
(0.0103)\end{array}$ & $\begin{array}{c}0.0073 \\
(0.0166)\end{array}$ \\
\hline Any Inheritance & $\begin{array}{l}0.0263^{\star \star} \\
(0.0111)\end{array}$ & $\begin{array}{l}-0.0365 \\
(0.0659)\end{array}$ & $\begin{array}{c}0.0131 \\
(0.0246)\end{array}$ & $\begin{array}{l}-0.0039 \\
(0.0216)\end{array}$ & $\begin{array}{l}0.0335^{\star \star} \\
(0.0145)\end{array}$ & $\begin{array}{l}-0.0034 \\
(0.0035)\end{array}$ & $\begin{array}{c}0.00 \\
(0.0058)\end{array}$ & $\begin{array}{c}0.0142 \\
(0.0097)\end{array}$ & $\begin{array}{l}-0.0034 \\
(0.0149)\end{array}$ \\
\hline Dependent Variable Mean & 0.8916 & 7.0120 & 0.6358 & 0.7420 & 0.1954 & 0.0131 & 0.0443 & 0.9300 & 0.2243 \\
\hline$N$ & 36729 & 32566 & 29976 & 36701 & 29973 & 36705 & 36625 & 36497 & 36685 \\
\hline
\end{tabular}

Note: See notes on Tables 3 and 4 for additional details on estimation process and supplementary covariates. OOP refers to out-of-pocket medical expenditure. All dependent variables, other than the log of out-of-pocket spending, are dichotomous with estimates obtained from linear probability models. See the text for additional details on definitions of the dependent variables. 
Table 6. Predicted Effect of Inheritance Receipt on Alcohol Use

\begin{tabular}{|c|c|c|c|c|c|}
\hline & \multirow{2}{*}{$\begin{array}{l}\text { Current } \\
\text { Drinker }\end{array}$} & \multirow{2}{*}{$\begin{array}{l}\text { Log (\# Drinks } \\
\text { Per Day) if }>0\end{array}$} & \multicolumn{3}{|c|}{ Weekly Alcohol Consumption } \\
\hline & & & 1-7 Drinks & 1 - 14 Drinks & $>14$ Drinks \\
\hline & (1) & (2) & (3) & (4) & (5) \\
\hline Inheritance $\geq \$ 10,000$ & $\begin{array}{c}0.1010^{\star \star \star} \\
(0.0311)\end{array}$ & $\begin{array}{l}0.1070^{\star *} \\
(0.0440)\end{array}$ & $\begin{array}{l}0.0626^{\star *} \\
(0.0280)\end{array}$ & $\begin{array}{l}0.102^{\star \star \star} \\
(0.0317)\end{array}$ & $\begin{array}{c}0.0169 \\
(0.0120)\end{array}$ \\
\hline Any Inheritance & $\begin{array}{l}-0.0257 \\
(0.0285)\end{array}$ & $\begin{array}{c}-0.1380^{\star \star \star} \\
(0.0402)\end{array}$ & $\begin{array}{l}-0.0127 \\
(0.0245)\end{array}$ & $\begin{array}{l}-0.0190 \\
(0.0283)\end{array}$ & $\begin{array}{l}-0.0029 \\
(0.0105)\end{array}$ \\
\hline Dependent Variable Mean & 0.5127 & 0.5616 & 0.2442 & 0.3143 & 0.0398 \\
\hline$N$ & 36630 & 9834 & 27674 & 27674 & 27674 \\
\hline
\end{tabular}

Note: See notes on Tables 3 and 4 for additional details on estimation process and supplementary covariates. All dependent variables, other than log(\#drinks/day), are dichotomous with estimates obtained from linear probability models. See the text for additional details on definitions of the dependent variables. Information on the number of alcoholic beverages consumed is not available in wave 2 (1994), reducing the sample size in the last four columns. 
Table 7. Predicted Effect of Inheritance Receipt on Exercise, Smoking and Body Weight

\begin{tabular}{lcccc}
\hline \hline & $\begin{array}{c}\text { Vigorous } \\
\text { Exercise }\end{array}$ & Current Smoker & $\begin{array}{c}\text { Obese } \\
(\mathrm{BMI} \geq 30)\end{array}$ & $\begin{array}{c}\text { Severely Obese } \\
(\mathrm{BMI} \geq 35)\end{array}$ \\
\hline Inheritance $\geq \$ 10,000$ & $(1)$ & $(2)$ & $(3)$ & $(4)$ \\
Any Inheritance & 0.0098 & 0.0043 & -0.0287 & -0.0123 \\
& $(0.0292)$ & $(0.0180)$ & $(0.0199)$ & $(0.0116)$ \\
Dependent Variable Mean & -0.0123 & -0.0137 & 0.0213 & 0.0104 \\
& $(0.0257)$ & $(0.0159)$ & $(0.0185)$ & $(0.0108)$ \\
& 0.4840 & 0.2129 & 0.2576 & 0.0762 \\
\hline
\end{tabular}

Note: See notes on Tables 3 and 4 for additional details on estimation process and supplementary covariates. All dependent variables are dichotomous with estimates obtained from linear probability models. See the text for additional details on definitions of the dependent variables. 
Table A.1. Descriptive Statistics for Selected Variables

\begin{tabular}{|c|c|c|c|}
\hline & All & Females & Males \\
\hline \multicolumn{4}{|l|}{ Baseline (1992) Control Variables } \\
\hline Female & 0.5290 & 1.0000 & 0.0000 \\
\hline Less Than High School & 0.2417 & 0.2420 & 0.2414 \\
\hline GED & 0.0577 & 0.0486 & 0.0680 \\
\hline High school graduate & 0.3427 & 0.3833 & 0.2971 \\
\hline Some college & 0.1924 & 0.1989 & 0.1852 \\
\hline College graduate & 0.1654 & 0.1272 & 0.2084 \\
\hline Cohabits & 0.0205 & 0.0181 & 0.0232 \\
\hline Separate/Divorced & 0.0976 & 0.1188 & 0.0737 \\
\hline Widowed & 0.0444 & 0.0736 & 0.0118 \\
\hline Never married & 0.0220 & 0.0228 & 0.0212 \\
\hline Married & 0.8154 & 0.7667 & 0.8702 \\
\hline Log(household income) & 10.3377 & 10.2292 & 10.4595 \\
\hline \multicolumn{4}{|l|}{ Self reported health } \\
\hline Excellent & 0.2379 & 0.2446 & 0.2304 \\
\hline Very good & 0.2827 & 0.2949 & 0.2690 \\
\hline Good & 0.2701 & 0.2525 & 0.2898 \\
\hline Fair & 0.1315 & 0.1388 & 0.1233 \\
\hline Smoker & 0.2506 & 0.2412 & 0.2613 \\
\hline \multicolumn{4}{|l|}{ Death of Parent Since Last Survey } \\
\hline Mother & 0.0470 & 0.0445 & 0.0478 \\
\hline Father & 0.0322 & 0.0254 & 0.0337 \\
\hline \multicolumn{4}{|l|}{ Dependent Variables (in 2006) } \\
\hline Died By 2006 Survey & 0.1942 & 0.1435 & 0.2511 \\
\hline Fair/worse Self-Reported Health & 0.2764 & 0.2798 & 0.2720 \\
\hline Excellent Self-Reported Health & 0.1070 & 0.1034 & 0.1115 \\
\hline ADL & 0.1347 & 0.1401 & 0.1278 \\
\hline IADL & 0.0607 & 0.0500 & 0.0745 \\
\hline Depressed (CESD Score $\geq 3$ ) & 0.1953 & 0.2691 & 0.2371 \\
\hline Positive OOP medical expenditure & 0.9191 & 0.9302 & 0.9049 \\
\hline $\log (\mathrm{OOP})$ conditional on OOP $>0$ & $\begin{array}{c}7.3455 \\
(1.3672)\end{array}$ & $\begin{array}{c}7.3715 \\
(1.3659)\end{array}$ & $\begin{array}{c}7.3112 \\
(1.3685)\end{array}$ \\
\hline Hospital Episode & 0.2636 & 0.2507 & 0.2801 \\
\hline Outpatient Care & 0.2377 & 0.2245 & 0.2546 \\
\hline Nursing Home & 0.0236 & 0.0296 & 0.0158 \\
\hline Home Health Care & 0.0657 & 0.0646 & 0.0672 \\
\hline Visited Doctor & 0.9533 & 0.9632 & 0.9407 \\
\hline Prescription Use & 0.8583 & 0.8688 & 0.8449 \\
\hline Visited Dentist & 0.6372 & 0.6523 & 0.6178 \\
\hline Obese $(\mathrm{BMI} \geq 30)$ & 0.3024 & 0.3153 & 0.2860 \\
\hline Severely Obese (BMI $\geq 35)$ & 0.1038 & 0.1228 & 0.0797 \\
\hline Current Drinker & 0.5193 & 0.4621 & 0.5927 \\
\hline \multirow[t]{2}{*}{ Log(\# Drinks/Day) conditional on drinking } & 0.4922 & 0.3344 & 0.6229 \\
\hline & $(0.5483)$ & $(0.4361)$ & $(0.5956)$ \\
\hline 1-7 drinks per day & 0.2839 & 0.1744 & 0.2631 \\
\hline 1-14 drinks per day & 0.3584 & 0.1997 & 0.3145 \\
\hline Smoker & 0.2238 & 0.2712 & 0.1809 \\
\hline Vigorous Exercise & 0.4490 & 0.3992 & 0.5096 \\
\hline
\end{tabular}


Note: Sample is limited to whites providing data through 2006. Sample sizes are 5,217, 2,760 and 2,457 for all whites, white females and white males. Standard deviations are in parenthesis. Log incomes are calculated by adding $\$ 1$ to the value for persons reporting no income. Activity Daily Living (ADL) limitation if the respondent answers yes to having difficulty bathing, eating, moving from bed-to-chair, or walking by self. Instrumental activity of daily living (IADL) limitation if the respondent answers yes to having difficulty using telephone, shopping, managing money, preparing meals, or taking medication. Depression refers to scores of 3 or higher on the 8-item Center for Epidemiologic Studies Depression (CESD) scale. "OOP" refers to out of pocket medical expenditure. Current drinking refers to the consumption of alcoholic beverages within the last three months. Vigorous exercise refers to vigorous exercise three or more times per week. All baseline variables are measured in 1992, except for depression and smoking, where the data were first collected in 1994. The outcomes refer to values in 2006, except for vigorous exercise where questions were lacking in 2006 and so the variable refers to 2004. 